\title{
RESEARCH
}

\section{Fatal agricultural injuries in preschool children: risks, injury patterns and strategies for prevention}

\author{
Robert J. Brison, William Pickett, Richard L. Berg, James Linneman, Jamie Zentner, Barbara Marlenga
}

$\infty$

See related article page $\mathrm{I} 73 \mathrm{I}$

\section{ABSTRACT}

Background: Agricultural injuries are an important health concern for pediatric populations and particularly for children of preschool age. This study was conducted to estimate rates and determine patterns of fatal agricultural injury among young children exposed to agricultural hazards and to identify strategies to prevent such injuries.

Methods: A national case series was assembled retrospectively for the years 1990-2001. We identified children aged 1-6 years who were fatally injured during the course of agricultural work or through contact with a hazard of an agricultural worksite. Using a standardized survey instrument, we collected data from provincial coroners' and medical examiners' case files. Fatal agricultural injury rates (calculated with denominator data from the Canada Census of Agriculture) were compared with national all-cause, unintentional fatal injury rates in the general population of Canadian children during the same period (calculated with denominator data from the Canada Census of Population).

Results: The annual rate of fatal agricultural injury was substantially higher than that of all-cause, unintentional fatal injury among Canadian children aged $1-6$ years (14.9 v. 8.7 per 100000 person-years, respectively). Differences in risk were attributed to elevated fatal agricultural injury rates among boys. Most injuries occurred in the agricultural worksite, largely $(84 / 115[73 \%])$ the result of 3 mechanisms: being run over by agricultural machinery as a bystander (29\%) or as an extra rider who fell from the machine (22\%), or asphyxia due to drowning (23\%). Major crush injuries (of the head, chest and abdomen) and asphyxia from drowning were the most frequent mechanisms of injury.

Interpretation: Preschool-aged children exposed to agricultural worksites are at high risk of fatal injuries. Prevention strategies should focus on restricting children's access to these worksites. Physicians and allied health care professionals who care for rural families could take on a proactive role in communicating the nature and magnitude of these risks.

CMAJ 2006;174(I2):1723-6
$\mathrm{F}$ arms and ranches are often portrayed as wholesome settings with many beneficial attributes; nonetheless, pediatric agricultural injuries have long been recognized as an important injury-control problem. ${ }^{1,2}$ Children of preschool age are known to be at high risk of agricultural injury. ${ }^{3,4}$ Yet, characteristics of those killed in agricultural injury events and the events themselves have not been described in detail, which limits the information available to guide prevention efforts. A recent systematic review of programs designed to prevent childhood injuries at farms showed that those aimed at the very young were few, ${ }^{5}$ which reflects a poor understanding of the degree of risk faced by this vulnerable population.

We determined incidence rates and patterns of fatal agricultural injuries experienced by children aged I -6 years, to address 2 questions: To what extent do preschool children exposed to agricultural hazards on farms and ranches experience increased rates of fatal injury compared with the Canadian population of children aged I- 6 years? And are there patterns of agricultural injuries specific to this age group that could direct primary prevention efforts?

\section{Methods}

This study involved development of a national retrospective case series of fatal pediatric agricultural injuries. Queen's University Health Sciences Research Ethics Board approved the study protocol.

Personnel in all 10 Canadian provincial coroners' and medical examiners' offices identified fatal agricultural injuries among children aged 1-6 years from I990 through 200 I (no infants younger than 1 year died of unintentional farm-related injuries). A fatal agricultural injury was defined in advance as any unintentional injury resulting in death that occurred during activities related to the operation of a farm or ranch, or involved any hazard of a farm or ranch environment, excluding fatal non-work-related injuries that occurred in the farm or ranch residence. ${ }^{3}$ Investigative reports were reviewed for each case; their content varied, but included a death certificate and a report from the investigating coroner at minimum. Police and autopsy reports were sometimes available.

A standardized data-collection tool was developed from existing research instruments ${ }^{3}$ and administrative question- 
naires ${ }^{6,7}$ that covered case demographics and information on the activities and circumstances of each injury event. A study glossary, including a list of rules and procedures for data collection, was concurrently developed and refined. With the data collection instrument, the study investigators independently reviewed samples of 10-12 cases and entered the results into separate data tables for analysis. All discrepancies were identified and resolved, and refinement of the study glossary and definitions continued until a high level of agreement was reached, whereupon final data collection was initiated.

Cases reviewed during the initial process were included in the final case series. Subsequent checks of data quality ensured their reliability and accuracy, and their adherence to the rules and precedents in the study glossary.

Annual rates of fatal agricultural injuries and associated confidence intervals (CIs) were calculated using population denominator data from the 1996 Canada Census of Agriculture. ${ }^{8}$ Analogous all-cause unintentional fatal-injury rates

Table 1: Characteristics of children 1-6 years of age who died of an agricultural injury in Canada, 1990-2001

\begin{tabular}{|c|c|c|c|c|}
\hline \multirow[b]{2}{*}{ Characteristic of child or event } & \multicolumn{4}{|c|}{ No. (\%) of children killed } \\
\hline & $\begin{array}{c}\text { Male } \\
n=91\end{array}$ & & $\begin{array}{l}\text { male } \\
=24\end{array}$ & $\begin{array}{c}\text { Total } \\
n=115\end{array}$ \\
\hline \multicolumn{5}{|l|}{ Age of child, yr } \\
\hline 1 & $14(15)$ & 5 & $(21)$ & 19 (17) \\
\hline 2 & $14(15)$ & 6 & $(25)$ & $20(17)$ \\
\hline 3 & $23(25)$ & 3 & (13) & $26(23)$ \\
\hline 4 & $15(16)$ & 3 & $(13)$ & $18(16)$ \\
\hline 5 & $11(12)$ & 4 & (17) & $15(13)$ \\
\hline 6 & $14(15)$ & 3 & $(13)$ & $17(15)$ \\
\hline \multicolumn{5}{|l|}{ Child lived on farm or ranch } \\
\hline Yes & $74(81)$ & 19 & (79) & $93(81)$ \\
\hline No & $12(13)$ & 4 & $(17)$ & $16(14)$ \\
\hline Unknown & $5 \quad(5)$ & 1 & (4) & $6 \quad(5)$ \\
\hline \multicolumn{5}{|c|}{ Child's relationship to farm/ranch owner } \\
\hline Child of owner & $72(79)$ & 20 & $(83)$ & $92(80)$ \\
\hline Other relative of owner & $10(11)$ & 0 & & 10 \\
\hline Relative of hired employee & 1 (1) & 1 & (4) & $2(2)$ \\
\hline Visitor & $2(2)$ & 2 & (8) & $4 \quad(3)$ \\
\hline Other or unknown & $6 \quad(7)$ & 1 & (4) & $7 \quad(6)$ \\
\hline \multicolumn{5}{|c|}{ Agricultural work was involved in injury } \\
\hline Yes & $66(73)$ & 20 & $(83)$ & $86(75)$ \\
\hline No & $21(23)$ & 4 & $(17)$ & $25(22)$ \\
\hline Unknown & $4 \quad(4)$ & 0 & & $4(3)$ \\
\hline \multicolumn{5}{|c|}{ Child was engaged in agricultural work } \\
\hline Yes & $3(3)$ & 0 & & $3(3)$ \\
\hline No & $88(97)$ & 24 & (100) & $112(97)$ \\
\hline \multicolumn{5}{|c|}{ Agricultural work hazard was involved } \\
\hline Yes & $72(79)$ & 22 & $(92)$ & $94(82)$ \\
\hline No & $19(21)$ & 2 & $(8)$ & $21(18)$ \\
\hline
\end{tabular}

(which included agricultural injuries) were calculated for children 1-6 years of age in the Canadian population with use of denominator data from the Canada Census of Population. ${ }^{9}$ Rate calculations by integer age group and sex were restricted to a common 10-year period (1990-1999 inclusive), for which numerator data were accessible from each source. Because the number of events was small, exact CIs were calculated with the assumption of a Poisson distribution. ${ }^{10,11}$ Descriptive statistics characterized the children's age, sex, residency (on or off the farm or ranch) and relation to the owner or a worker there; whether agricultural work was involved in the injury event and if the victim was engaged in it; the leading mechanisms of injury; and the anatomic nature of the main injury.

\section{Results}

From 1990 through 200I, II5 Canadian children I-6 years of age died of unintentional agricultural injuries (Table I). Almost $80 \%$ were male and almost $90 \%$, the child or another relative of a farm or ranch operator. Agricultural work was involved in $75 \%$ of the injury cases, although the injured children were rarely engaged in the work themselves (3\%).

Fatal agricultural injury rates exceeded national all-cause, unintentional fatal injury rates among Canadian children aged $\mathrm{I}-6$ years by $7 \mathrm{I} \%$ (Table 2 ); the excess was due to an elevated risk of agricultural injury experienced by boys. Among boys, the annual fatality rates from agricultural injuries alone exceeded all-cause rates by $120 \%$; among girls, agricultural rates were $7 \%$ lower. (Fatality rates among farm children

Table 2: Rates of unintentional fatal injuries in Canada among children 1-6 years old, 1990-1999

\begin{tabular}{crrrr}
\hline & \multicolumn{3}{l}{ Deaths $(95 \% \mathrm{Cl})$ per 100000 person-yr } \\
\cline { 2 - 5 } Sex and age, yr & \multicolumn{2}{c}{ All causes* } & \multicolumn{2}{c}{ Agricultural $\dagger$} \\
\hline Boys 1-6 & 10.4 & $(9.8-10.9)$ & 22.9 & $(18.2-28.4)$ \\
\hline 1 & 11.0 & $(9.6-12.6)$ & 26.2 & $(14.0-44.9)$ \\
\hline 2 & 12.1 & $(10.7-13.8)$ & 22.3 & $(11.5-39.0)$ \\
3 & 12.7 & $(11.2-14.3)$ & 38.7 & $(24.2-58.5)$ \\
\hline 4 & 10.5 & $(9.1-11.9)$ & 21.9 & $(12.0-36.7)$ \\
\hline 5 & 8.8 & $(7.6-10.2)$ & 15.0 & $(7.2-27.5)$ \\
\hline 6 & 7.3 & $(6.2-8.5)$ & 16.8 & $(8.7-29.3)$ \\
\hline Girls 1-6 & 6.9 & $(6.4-7.4)$ & 6.4 & $(4.0-9.7)$ \\
\hline 1 & 9.3 & $(7.9-10.7)$ & 8.8 & $(2.4-22.6)$ \\
\hline 2 & 7.6 & $(6.4-9.0)$ & 9.7 & $(3.1-22.5)$ \\
\hline 3 & 6.8 & $(5.7-8.1)$ & 5.5 & $(1.1-16.1)$ \\
\hline 4 & 6.2 & $(5.2-7.4)$ & 5.2 & $(1.1-15.3)$ \\
\hline 5 & 5.7 & $(4.8-6.9)$ & 6.2 & $(1.7-15.9)$ \\
\hline 6 & 5.9 & $(4.9-7.0)$ & 4.4 & $(0.9-12.8)$ \\
\hline All, 1-6 & 8.7 & $(8.3-9.0)$ & 14.9 & $(12.2-18.0)$ \\
\hline
\end{tabular}

Note: $\mathrm{Cl}=$ confidence interval.

*Includes nonagricultural causes of fatal trauma (e.g. nonagricultural vehicle collisions, injuries in the home) that took place in agricultural settings.

†Excludes nonagricultural causes of fatal trauma. 
would be somewhat higher if deaths from nonagricultural causes had been included.)

Three mechanisms of injury accounted for $73 \%$ of the deaths from injuries related to agricultural settings (Table 3 ): runovers of bystander children within the worksite, drowning (mainly in farm ponds or dugouts and in manure lagoons) and runovers of children who had fallen from tractors or other agricultural machines they were riding as passengers. The predominant lethal injuries were major crush injuries to the head or neck, drowning-related asphyxia and crushing injuries to the chest. These patterns of injury occurrence varied by sex, although caution must be exercised in these comparisons because so few cases were observed among girls.

\section{Interpretation}

The high risks of serious injury to children and youth exposed to agricultural hazards have been well established. ${ }^{1,4,12}$ By focusing our analysis on farm children who died before the age of 7 years, specific patterns of injury were revealed. These young children had a greater risk of fatal injury than other children of the same age in Canada. Although preschool-aged farm children rarely participated in agricultural work activities and theoretically should be protected from worksite-related injury, they nevertheless do experience a high risk of fatal trauma because they are present at the worksite while others do agricultural work. These deaths most typically occurred among boys $(79 \%)$ accompanying a parent to the farm or ranch worksite. Children are most often killed by drowning in farm ponds or manure lagoons, or after sustaining nonsurvivable crush injuries to the head or trunk when run over by farm equipment.

Several potential limitations of this research warrant recognition. First, these coroners' data were collected for administrative purposes and not specifically for injury research. Although we have no information on the reliability of recordkeeping in the original coroners' files or how coding might vary between provinces, any effect would cause an underestimate of the risks presented. Second, data were not collected from the Canadian Territories, where agricultural activities are limited (which is why they are not included in the Canadian Census of Agriculture). Third, denominators for rate calculations were estimated with data from the 1996 Canadian Census of Agriculture, as per established precedent. ${ }^{3}$ This may result in minor variance in the accuracy of risk estimates compared with the use of annualized denominator data, had they been available.

Our findings suggest a need for the development of simple prevention strategies to effectively remove children from the vicinity of known occupational hazards. Interventions, including engineering solutions (both physical and social) and regulatory approaches to injury control, may hold promise in prevention of these fatal agricultural injuries. Possible physicalengineering interventions include the construction of secure, dedicated play areas to separate children from the workplace, and the installation of passive safety barriers (e.g., gated fences) around known hazards such as machinery compounds and water sources. ${ }^{13}$ Social-engineering strategies include the creation of "child-free" zones on farms and ranches, supported by enhanced access to daycare options for rural popula-
Table 3: Mechanism and nature of the main injury in cases of fatal agricultural injury in Canada to children 1-6 years of age, 1990-1999

\begin{tabular}{|c|c|c|c|}
\hline \multirow[b]{2}{*}{ Aspect } & \multicolumn{3}{|c|}{ No. of children killed (\%) } \\
\hline & $\begin{array}{l}\text { Male } \\
n=91\end{array}$ & $\begin{array}{c}\text { Female } \\
n=24\end{array}$ & $\begin{array}{l}\text { Total } \\
n=115\end{array}$ \\
\hline \multicolumn{4}{|l|}{ Mechanism of injury } \\
\hline Runover of bystander & $21(23)$ & $12(50)$ & $33(29)$ \\
\hline Drowning & $21(23)$ & $5(21)$ & $26(23)$ \\
\hline Runover of passenger/operator & $22(24)$ & $3(12)$ & $25(22)$ \\
\hline $\begin{array}{l}\text { Caught in/under/between } \\
\text { machines or objects }\end{array}$ & $9(10)$ & 0 & $9 \quad(8)$ \\
\hline Pinned or struck by object & $3(3)$ & $2(8)$ & $5 \quad(4)$ \\
\hline Rollover of tractor & 3 (3) & 0 & $3(3)$ \\
\hline Other & $12(13)$ & $2(8)$ & $14(12)$ \\
\hline \multicolumn{4}{|l|}{ Anatomical nature of main injury } \\
\hline Major trauma to head & $43(47)$ & $16(67)$ & $59(51)$ \\
\hline Asphyxia from drowning & $21(23)$ & $5(21)$ & $26(23)$ \\
\hline Chest injury/crush & $11(12)$ & $2(8)$ & $13(11)$ \\
\hline Abdominal injury & $6 \quad(7)$ & 0 & $6 \quad(5)$ \\
\hline Asphyxia not from drowning & $6 \quad(7)$ & 0 & $6 \quad(5)$ \\
\hline Other & $4 \quad(4)$ & $1(4)$ & $5 \quad(4)$ \\
\hline
\end{tabular}

tions, especially during busy fieldwork seasons. The federal focus on the provision of feasible and cost-effective childcare for all Canadian families ${ }^{14}$ may provide new opportunities for the protection of preschool children who are exposed to agricultural hazards.

For any preventive strategy to be effective in this setting, the initial priority must be to promote understanding of the magnitude and severity of this injury problem among rural families, their communities, the urban majority and policy makers. As providers of regular care to children and as general advocates for rural health, physicians and allied health professionals in agricultural communities may have a role in promoting risk awareness. Our findings suggest that discussions with farm parents about high-risk activities should include advice that they never permit small children to ride as passengers on tractors and other agricultural machinery, and that they stop young children from visiting agricultural worksites under any circumstances. ${ }^{15}$ The agricultural worksite must be viewed as an entity separate from the agricultural residence. Prohibiting young children's access to a worksite is standard practice in virtually all other industries. Communicating the frequency of these injuries among young children and their risks of injury when exposed to the hazards on farms and ranches will be an important first step in generating effective solutions to protect young children from agricultural injuries.

\section{This article has been peer reviewed.}

From the Departments of Emergency Medicine and of Community Health and Epidemiology, Queen's University and Kingston General Hospital Clinical Research Centre (Brison, Pickett), Kingston, Ont.; and the Department 
of Biostatistics (Berg, Linneman) and National Children's Center for Rural and Agricultural Health and Safety (Zentner, Marlenga), Marshfield Clinic Research Foundation, Marshfield, Wis.

Competing interests: None declared.

Contributors: Robert Brison, William Pickett and Barbara Marlenga contributed to the study conception and design, data acquisition and drafting of the manuscript. Richard Berg and James Linneman were responsible for statistical analysis. Jamie Zentner was responsible for data acquisition. All authors participated in the critical revision of the manuscript and approved the final version for publication.

Acknowledgements: We thank Deborah Emerton and Catherine Isaacs of the Kingston General Hospital Clinical Research Centre for administrative support and assistance with editing the manuscript. We are grateful to all those who helped provide data for this case series, including the provincial coroners' offices: Office of the Chief Medical Examiner, Province of Manitoba; Chief Coroner's Office of Saskatchewan; Office of the Chief Medical Examiner of Alberta; Terry Smith, Chief Coroner, and Tej Sidhu, Office of the Chief Coroner, Province of British Columbia; Me Pierre Morin, Coroner, Province of Quebec; Dr. Barry McLellan, Chief Coroner of Forensic Services, and June Lindsell, Office of the Chief Coroner of Ontario. We also thank Dr. Louise Paré, St-Ferreol-les-Neiges, Quebec, for assistance with translation of the documents at the Quebec Coroner's office, and Marshfield Clinic Research Foundation for the assistance of Linda Weis, Alice Stargardt and Jennifer Hayes in the preparation of this article.

This study was sponsored by the US Centers for Disease Control and Prevention, National Institute for Occupational Safety and Health (grant ROI OHo4205) and Ontario's Ministry of Health and Long-Term Care through a Career Scientist award to Dr. William Pickett.

\section{REFERENCES}

I. Rivara FP. Fatal and non-fatal farm injuries to children and adolescents in the United States, 1990-3. Inj Prev 1997;3:190-4.

2. Committee on Injury and Poison Prevention and Committee on Community Health
Services, American Academy of Pediatrics. Prevention of agricultural injuries among children and adolescents. Pediatrics 200I;108:I0I6-9.

3. Canadian Agricultural Injury Surveillance Program. Agricultural injuries in Canada for I990-2000. Kingston (Ont.): Queen's University; 2003

4. Pickett W, Brison RJ, Berg RL, et al. Pediatric farm injuries involving non-working children injured by a farm work hazard: five priorities for primary prevention. Inj Prev 2005;II:6-II.

5. Hartling L, Brison RJ, Crumley ET, et al. A systematic review of interventions to prevent childhood farm injuries. Pediatrics 2004;II4:e483-96.

6. US Department of Agriculture. 1997 census of agriculture: United States summary and state data (Vol. I, Part 5I). Washington: The Department; I999. Available: www.nass.usda.gov/census/census97/volumer/toc297.htm (accessed 2006 May 2).

7. Statistics Canada. Agricultural profile of Canada. Ottawa: The Ministry; I997. Cat no 93-356-XPB.

8. Statistics Canada. Profile of the Canadian farm population ages 0-6 [special data run by Eastern Ontario Health Information Partnership with files from the Canada Census of Agriculture]. Ottawa: The Ministry; 1997.

9. Child Health Division, Health Canada. Fatal injuries to children o-6 years in Canada, I990-2000 [special data run from the Canada Mortality Database]. Ottawa: The Ministry; 2003.

Io. Barker L. A comparison of nine confidence intervals for a Poisson parameter when the expected number of events is $\leq 5$. Am Stat 2002;56:85-9.

II. Guenther WC. Concepts of statistical inference. 2 nd ed. New York: McGraw-Hill; 1973.

I2. Pickett W, Brison RJ, Hoey JR. Fatal and hospitalized agricultural machinery injuries to children in Ontario, Canada. Inj Prev 1995;I:97-I02.

13. Marshfield Clinic. Creating safe play areas on farms. Available through www.cdc .gov/niosh/childag or at www.marshfieldclinic.org/nfmc/pages/default.aspx?page =nfmc_nccrahs_safe_play_background (accessed 2006 May 2).

I4. Government of Canada. Speech from the throne to open the first session of the 38th Parliament of Canada. Available: www.pco-bcp.gc.ca/default.asp?Language $=$ E\&Page $=$ sftddt\&doc $=$ sftddt2004_2_e.htm (accessed 2006 Mar 23).

I5. Pickett W, Marlenga B, Berg RL, et al. Growing up on the farm: some kids don't Agric Saf Health 2003;9:183-4.

Correspondence to: Dr. Barbara Marlenga, National Children's Center for Rural and Agricultural Health and Safety, Marshfield Clinic Research Foundation, Iooo North Oak Ave., Marshfield WI 54449, USA; fax 715 389-4996; marlenga.barbara@mcrf.mfldclin.edu

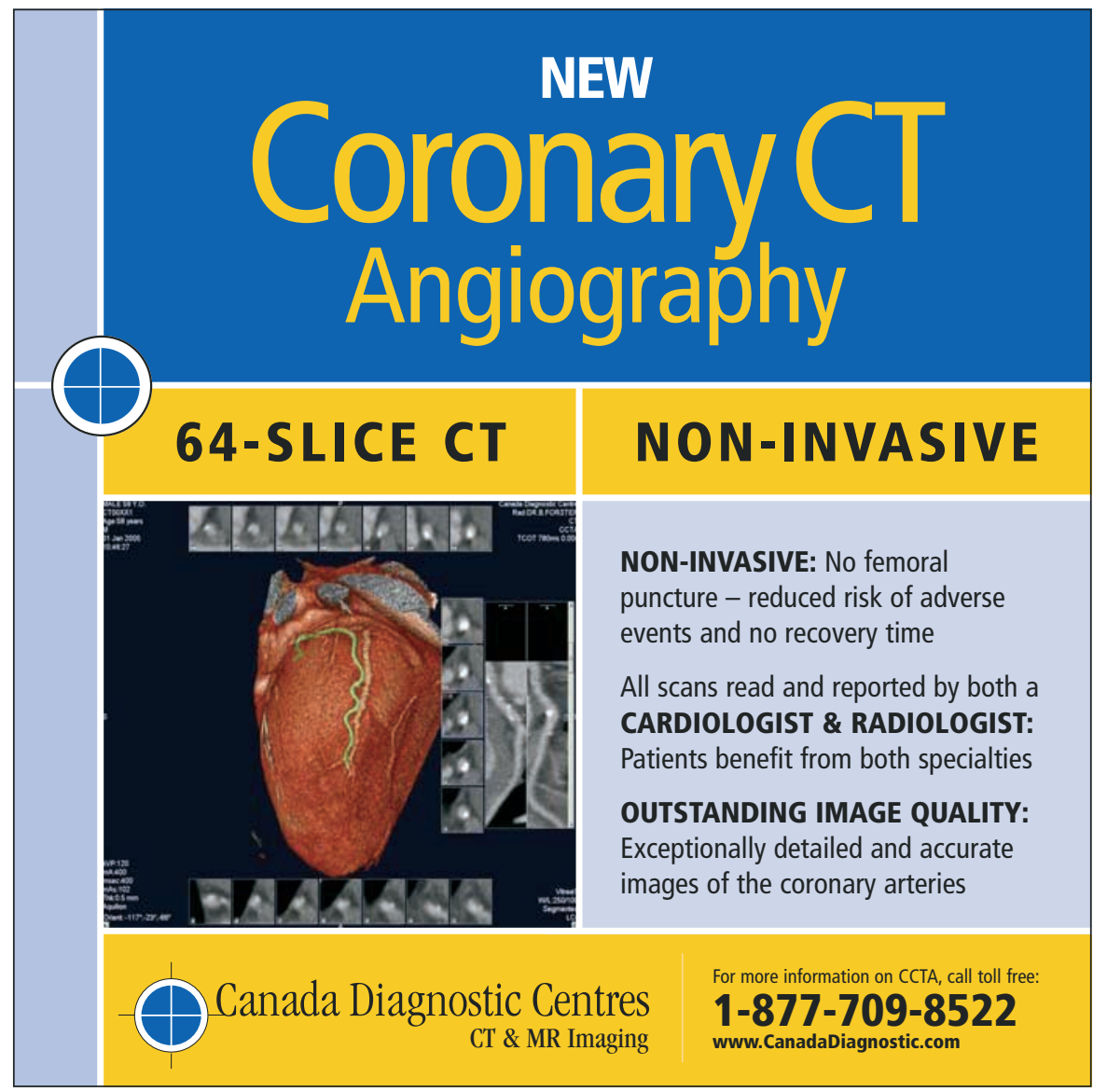

